\title{
Solubility and Dissolution Enhancement of Meropenem by Nano Suspension Approach
}

\author{
Srinivasa Kumari Chirumamilla ${ }^{1}$, Uma Devi Padasala² ${ }^{2}$ Haritha Aravally ${ }^{2}$, Lavakumar Vuppalapati ${ }^{3}$, Sowmya Cherukuri* \\ 'OTPRI, Jawaharlal Nehru Technological University Ananthapur, Anathapuramu-Andhra Pradesh, INDIA. \\ ${ }^{2}$ Raghavendra Institute of Pharmaceutical Education and Research, K.R. Palli cross, Near S.K. University, Anathapuramu, Andhra Pradesh, INDIA. \\ ${ }^{3}$ Arulmigu Kalasalingam College of Pharmacy, Anand Nagar, Krishnankoil, Srivilliputtur(Tk), Virudhunagar, Tamil Nadu 626126, INDIA.
}

\begin{abstract}
Objective: To prepare and evaluate the suitable nanosuspensions of Meropenem (BCS-IV drug) to increase its solubility and dissolution. Methodology: The meropenem nanosuspensions were prepared by emulsification solvent evaporation technique by applying ultrasonic energy through probe sonicator, where the organic phase of drug solution in methanol was emulsified in aqueous phase containing hydroxy propyl methyl cellulose as solubilizer and sodium lauryl sulphate as stabilizer. The prepared nanosuspensions were characterised for particle size zeta potential, surface morphology by SEM, drug excipient compatibility by FTIR and DSC and conducted in-vitro drug release studies. Results: Results showed that the prepared nanosuspensions were having particle size range from 1 to $1000 \mathrm{~nm}$ and the zeta potential from -10 to $-20 \mathrm{mVs}$. Scanning electron microscopic pictures revealed that the obtained nanosuspension particles were spherical in shape with surface smoothness and in-vitro drug release studies notified that the prepared nanosuspensions showed increase in solubility and dissolution of meropenem when compared with the pure form. Conclusion: The
\end{abstract}

nanosuspensions of meropenem could be successfully prepared and can be concluded that the nanosuspension formulation is a promising approach to increase the solubility and dissolution of BCS-IV drugs like meropenem.

Key words: BCS-IV drug, Nanosuspensions, Solubility, Dissolution, Emulsification and Solvent Evaporation.

\section{Correspondence:}

Sowmya Cherukuri, Head, Dept of Pharmaceutics, Raghavendra Institute of Pharmaceutical Education and Research, K.R. Palli cross, Near S.K. University, Anathapuramu, Andhra Pradesh, INDIA.

Phone no: +919550334547

E-mail: drsowmyariper@gmail.com.

DOI: 10.5530/jyp.2017.9.84

\section{INTRODUCTION}

Oral route is the most common and popular route for administration of drugs. ${ }^{1}$ More than $40 \%$ of the new chemically synthesized drugs being generated through drug discovery programmers are poorly watersoluble or lipophilic compounds (BCS in class II and IV). ${ }^{2}$ The uptake of poorly soluble drugs cannot be completed within the time at absorption site due to slow dissolution rate and generation of a low concentration gradient across the gastrointestinal tract leading to possibilities of gastric decomposition of drug due to longer gastrointestinal residence time and low bioavailability. ${ }^{3}$ This type of drugs has always been a challenging problem to pharmaceutical scientists in formulating suitable dosage forms. ${ }^{4}$ Solubility may be stated in units of concentration, molality, mole fraction, mole ratio, and other units. ${ }^{5}$ Meropenem is a broad-spectrum carbapenem antibiotic $^{6}$ and classified as BCS class IV drug ${ }^{7}$ means having low solubility and low permeability. Various approaches have be studied to overcome the solubility issues and unpleasant breath odour of active pharmaceutical ingredients belongs to BCS - II and IV. ${ }^{8}$ Meropenem exerts its action by penetrating bacterial cells readily and interfering with the synthesis of vital cell wall components, ${ }^{9}$ which leads to cell death. Hence, there is a need to increase its solubility and dissolution of drug in the body fluids to increase its bioavailability.

\section{MATERIAL AND METHODS}

Meropenem was obtained as gift sample from Aurobindo Pharma Ltd. Hyderabad. Sodium lauryl sulphate [SLS], Hydroxy Propyl Methyl Cellulose [HPMC-E-15] were purchased from the S.d. Fine Chemicals pri- vate limited, Mumbai and other reagents and chemicals used in the study are analytical grade.

\section{Method of Preparation \\ Emulsification solvent evaporation method}

The Meropenem nanosuspensions were prepared by emulsification solvent evaporation technique. ${ }^{10}$ Drug $(400 \mathrm{mg})$ and HPMC $(100 \mathrm{mg})$ was dissolved in $10 \mathrm{ml}$ of DCM and methanol (solvent) $(5 \mathrm{ml})$ at room temperature. This solution was poured into fixed amount $(50 \mathrm{ml})$ of non-solvent (Water) containing SLS (100 mg) as surfactant stabilizer at the same temperature. Subject the mixture to ultrasonic waves for 15 minutes followed by mechanical stirring for 20 minutes. The prepared nanosuspension was left stirred for $1 \mathrm{hr}$ at room temperature to evaporate the organic solvent. Centrifuge the dispersion and collected the nanosuspension. Different formulations were prepared by changing the concentration of polymer. The formulation details of meropenem nanosuspensions are shown in Table 1.

\section{Evaluation Studies}

Prepared nanosuspensions were evaluated for various characteristics.

\section{Solubility Studies}

The solubility studies on nanosuspensions were performed by adding the excess amount of dried nanosuspension powder to $10 \mathrm{ml}$ phosphate buffer of $\mathrm{pH}$ 6.8. The sealed flasks were agitated on an orbital shaker for 
$12 \mathrm{hr}$ at $37^{\circ} \mathrm{C}$. Then samples were centrifuged at $8000 \mathrm{rpm}$ for $10 \mathrm{~min}$ with high speed centrifuge (REMI R-8C, REMI laboratory Instruments, Bombay.) and the solutions were filtered using $0.45 \mu$ porous membrane filters before U.V analysis at $293 \mathrm{~nm}$.

\section{Drug - Excipient compatibility studies}

The solid state characteristics of drug are known to have a significant influence on the solubility parameter. ${ }^{11}$ Samples for analysis were prepared by mixing 50:50 ratio of drug and excipients. Then analysed by DSC (METTLER TOLEDO 822E equipment using E star software). The samples were taken separately in a pierced aluminium crucible with a capacity of $40 \mu \mathrm{l}$ and evaluated in the temperature ranging from 25 $250^{\circ} \mathrm{C}$ at a heating of $10^{\circ} \mathrm{C} / \mathrm{min}$ with a stream of nitrogen. Drug excipient compatibility is further studied by FTIR spectroscopy (BRUKER Alpha, Bombay) in the wave number region of 400 to $4000 \mathrm{Cm}^{-1}$.

\section{Particle Size}

The particle size of nanosuspensions were measured using Malvern Zetasizer ZS200. The particle size has inverse relationship with solubility. ${ }^{12}$

\section{Zeta potential}

Zeta potential can greatly influence the stability of nanosuspensions. ${ }^{4}$ For an electrostatic stability nanosuspension should have zeta potential a minimum of $\pm 30 \mathrm{mVs}$. For combined electrostatic and steric stabilization a minimum of $\pm 20 \mathrm{mV}$ is required. The zeta potential of nanosuspension was measured using Malvern Zetasizer ZS200 at $25 \pm 0.5^{\circ} \mathrm{C}$.

\section{Drug Content}

The nanosuspensions equivalent to $40 \mathrm{mg}$ of drug was transferred to a volumetric flask $(25 \mathrm{ml})$ dissolved and made up to $25 \mathrm{ml}$ with methanol. Then suiable dilutions were made with phosphate buffer of $\mathrm{pH} 6.8$ and drug content was analyzed against blank by UV spectrophotometer at $293 \mathrm{~nm}$.

\section{Entrapment efficiency}

The freshly prepared nanosuspensions were centrifuged at $2000 \mathrm{rpm}$ for $20 \mathrm{~min}$ at $25^{\circ} \mathrm{C}$ temperature using high speed centrifuge. The amount of incorporated drug was measured by taking the absorbance of the appropriately diluted $25 \mathrm{ml}$ of supernatant solution at $293 \mathrm{~nm}$ using UV spectrophotometer against blank/control nanosuspensions. Entrapment efficiency was calculated using the following formula:

\section{$\%$ Entrapment efficiency $=\frac{\text { Drug content }}{\text { Drug added in each formulation }} \mathrm{X} 100 .{ }^{13}$}

\section{Morphological examination}

The morphological examination of the prepared nanosuspension was studied by subjecting to SEM analysis.

\section{Scanning electron microscopy (SEM)}

The solid particle morphology of pure drug and nanosuspension were studied by using SEM analysis. A drop of drug nanosuspension was dispersed and mounted on aluminium stub covered with a glass lamella, air dried under vacuum and then examined. The SEM photo images were shown in Figure 5.

\section{Dissolution efficiency}

Dissolution efficiency ( $\mathrm{DE}_{30 \mathrm{~min}}$ ) of nanosuspension at $30 \mathrm{~min}$ was calculated from the data of in vitro dissolution studies by using the following formula. ${ }^{14}$

\section{$D E$ at $30 \mathrm{~min}=\frac{\mathrm{AUC} \text { at } 30 \mathrm{~min}}{\text { Total AUC at } 30 \mathrm{~min}} \times 100$}

The obtained $\mathrm{DE}_{30}$ values are shown in Table2.

\section{In-vitro dissolution studies}

In-vitro dissolution studies were performed by using USP apparatus IIRotating paddle (Electrolab-TDT-101, Bombay) using phosphate buffer $\mathrm{pH} 6.8$ at $50 \mathrm{rpm}$ speed and $37 \pm 0.5^{\circ} \mathrm{C}$ temperature. Transferred 900 $\mathrm{mL}$ of dissolution medium into each of the vessels. After attaining the required temperature transferred nanosuspension equivalent to $40 \mathrm{mg}$ of drug into each of the dissolution vessel and start immediately. At specific time points, withdrew $5 \mathrm{ml}$ of the sample from each of the dissolution vessels. Filter the solution through $0.45 \mu \mathrm{m}$ membrane filter. Maintain sink condition by adding $5 \mathrm{ml}$ of the fresh buffer into each dissolution vessel immediately. Quantitative analysis of meropenem was performed using UV spectrophotometer (Shimatzu UV-1800) at $293 \mathrm{~nm}$.

\section{In vitro release kinetics}

The mathematical models are used to evaluate the kinetics and mechanism of drug release from the nanosuspensions. The model that best fits the release data is selected based on the correlation coefficient $\left(r^{2}\right)$ value in various models. Excipients increase drug dissolution rate by increasing active drug surface area in contact with the dissolution medium. ${ }^{15}$ The correlation coefficient values of various kinetic models are shown in Table 2.

Stability studies were performed by storing the nanosuspensions at accelerated conditions as per ICH guidelines.

\section{RESULTS AND DISCUSSION}

Nano suspension approach is currently using method to enhance the solubility, dissolution rate there by bioavailability of poorly water soluble drugs. Nano suspensions consist of poorly water soluble drugs size below $1 \mu \mathrm{m}$ with or without any matrix material, ${ }^{16}$ which are stabilized by surfactants and polymers. ${ }^{17}$ In the present study various meropenem nanosuspensions were prepared by emulsification solvent evaporation technique. The formed nano formulations were almost spherical and uniform in size.

\section{Solubility}

The solubility studies performed for all the nanosuspension. The formulation F8 showed high solubility when compared to other formulations and it was clearly showed that increased in solubility of drug in nano form when compared with pure drug, it may be due to decrease in particle size and increased solubilisation.

\section{Drug - Excipient compatibility studies}

The DSC studies were performed for drug and drug-excipient mixture, it was found sharp endothermic peak at $129^{\circ} \mathrm{C}$ in Figure 1, which is due to the crystalline nature of drug. When DSC thermo gram of drug excipient mixture (figure 1) is compared with drug,it was observed that slight shift in the peak towards lower temperature is due to change in the physical state of drug on formulation. ${ }^{18}$ DSC and FTIR studies (Figure 2) proved the absence of drug excipient interactions.

\section{Particle size analysis}

The particle size of meropenem nanosuspensions from all the formulations was found to be in the range of 2.0 to $1652.4 \mathrm{~nm}$. Batch F8 had less 


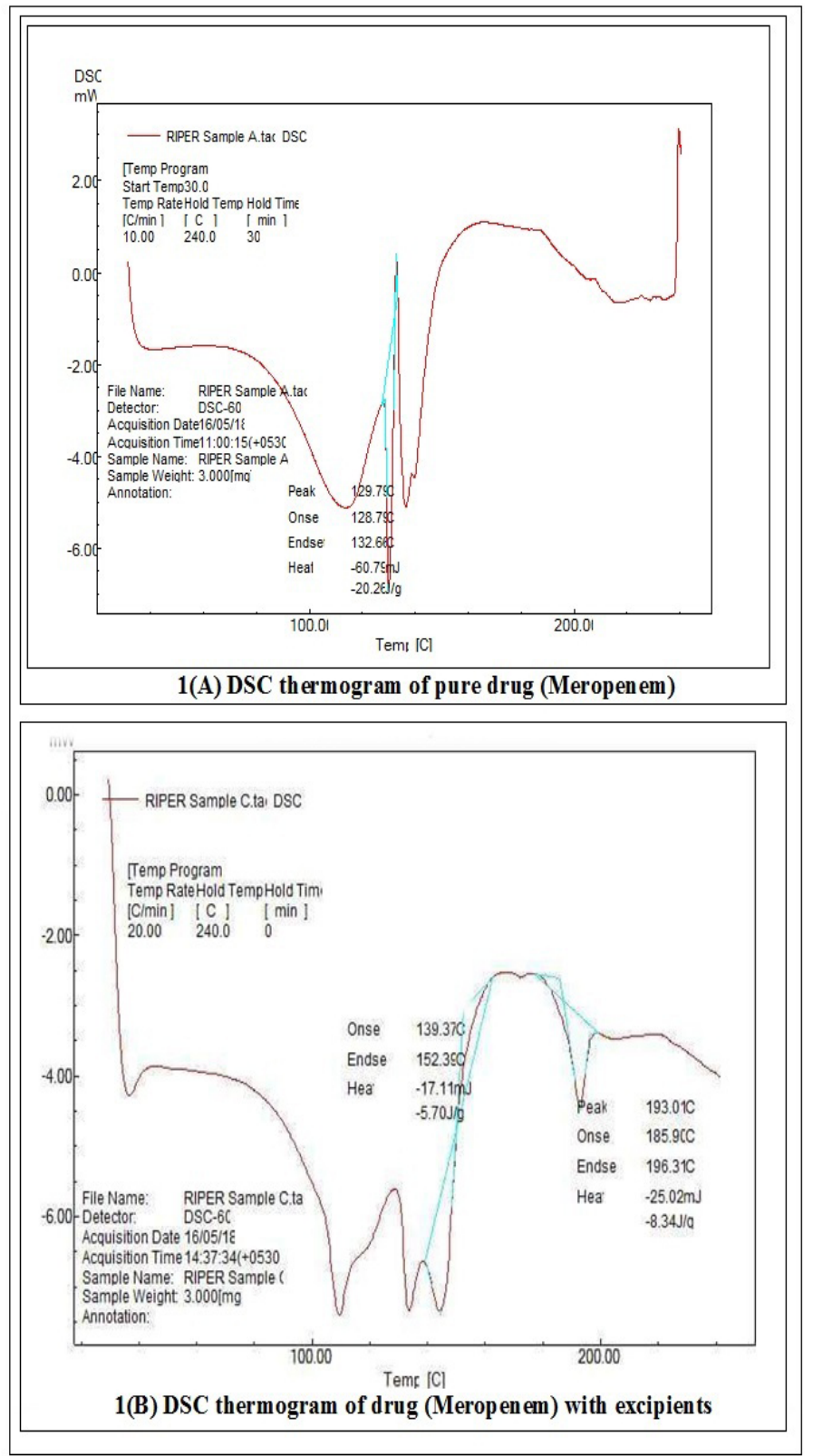

Figure 1: DSC Thermograms of pure meropenem and meropenem with the excipients.

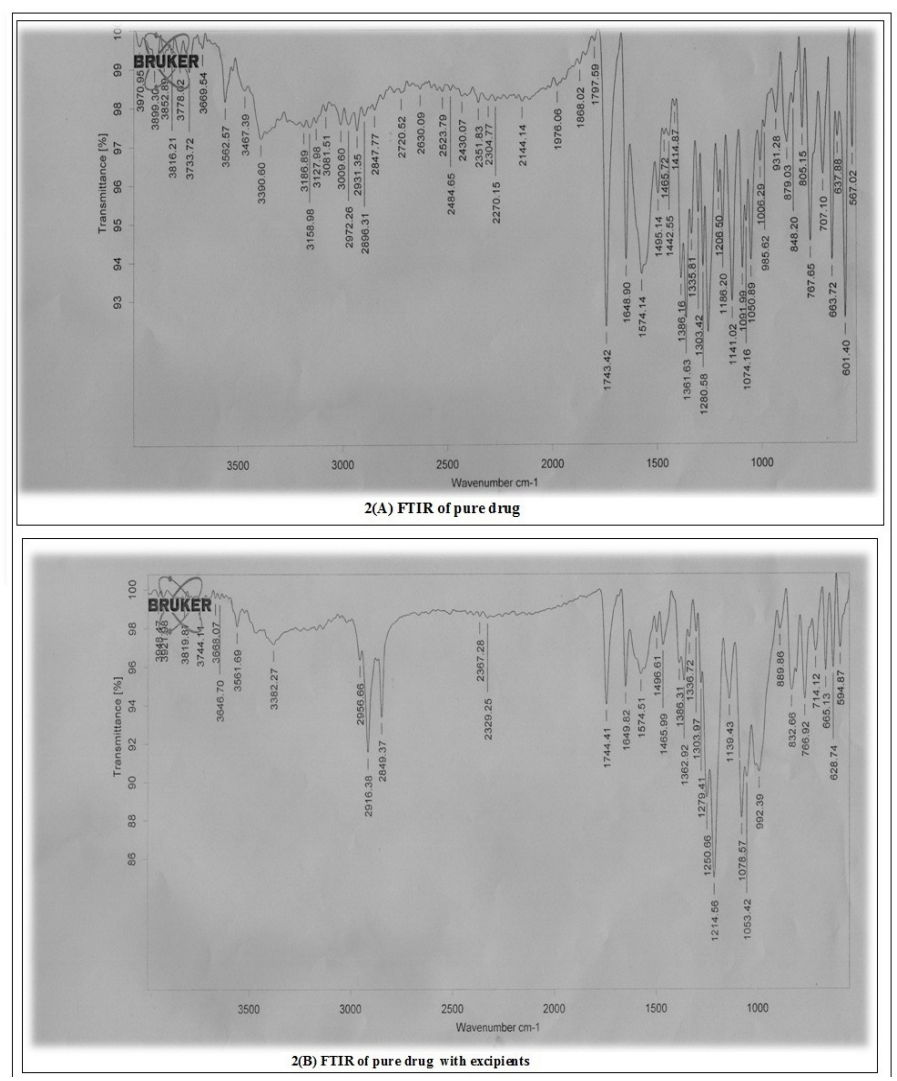

Figure 2: FTIR Spectras of pure meropenem and meropenem with excipients.

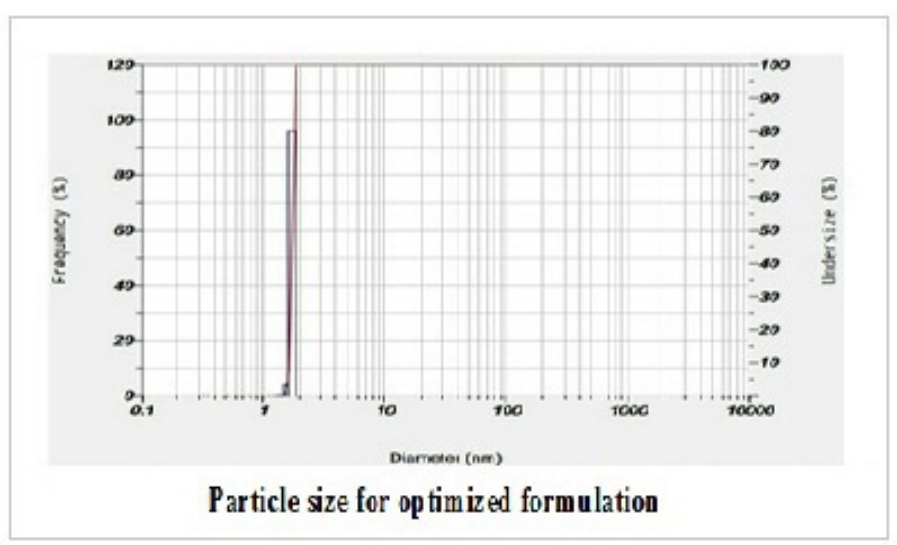

Figure 3: particle size of optimised nanosuspension formulation (F8).

\section{Scanning Electron Microscopy}

The nanosuspensions surface appearance and shape were analyzed by scanning Electron microscope (SEM). Figure 5 showed shape and surface appearance of the prepared nanosuspension and were found to be spherical in loose aggregates with surface smooth texture.

\section{Drug content}

The drug content was analysed for 10 formulations and the results were given in Table 2. The drug content of all formulation was found to be in the range of $90.24 \%$ to $95.62 \%$ and these values are within the pharmacopoeial limit. 


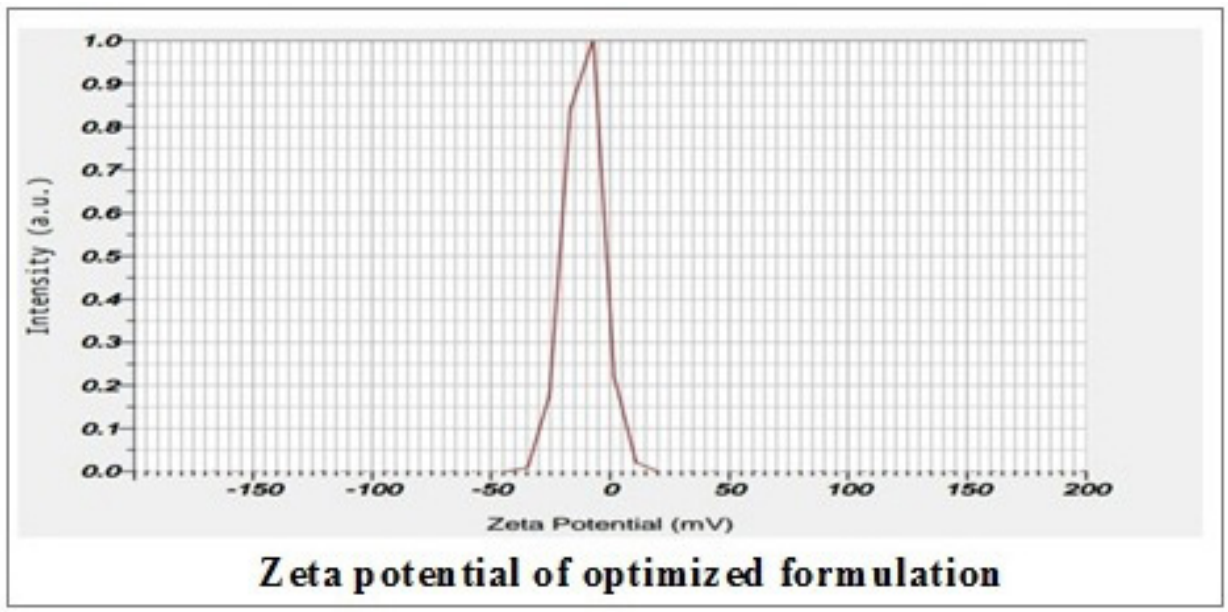

Figure 4: Zeta potential graph of optimised nanosuspension formulation (F8).

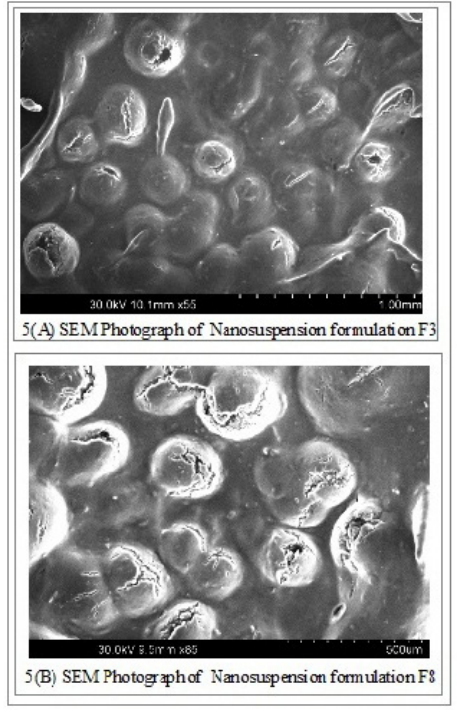

Figure 5: SEM Pictures of meropenem Nanosuspensions.

\section{Entrapment efficiency}

The entrapment efficiency of 10 formulations were calculated. The $\%$ entrapment efficiency of all formulations was found in the range of 52.5\% to $92.6 \%$. Results of particle size, zeta potential, drug content, solubility, drug content, and entrapment efficiency were shown in Table 2.

\section{In vitro drug release studies and dissolution efficiency}

It is evident from the in vitro drug release studies that, pure meropenem showed $8.6 \%$ of drug release at the end of $60 \mathrm{~min}$ it may be attributed to its higher hydrophobic and crystalline nature. Whereas the nanosuspension formulations showed more than $50 \%$ drug release at the end of $60 \mathrm{~min}$. The optimized nanosuspension (F8) shows $97.7 \%$ drug release at the end of $60 \mathrm{~min}$. The dissolution profiles of the pure drug and nanosuspensions are shown in the Figure 6. The dissolution efficiency of all the formulations was calculated. The dissolution efficiency of optimized formulation was quite higher (92.6\%) when compared to other formulations. From Table 2, it was found that $\mathrm{r}^{2}$ value of first order was greater than zero order value. The kinetic profiles of zero and first order

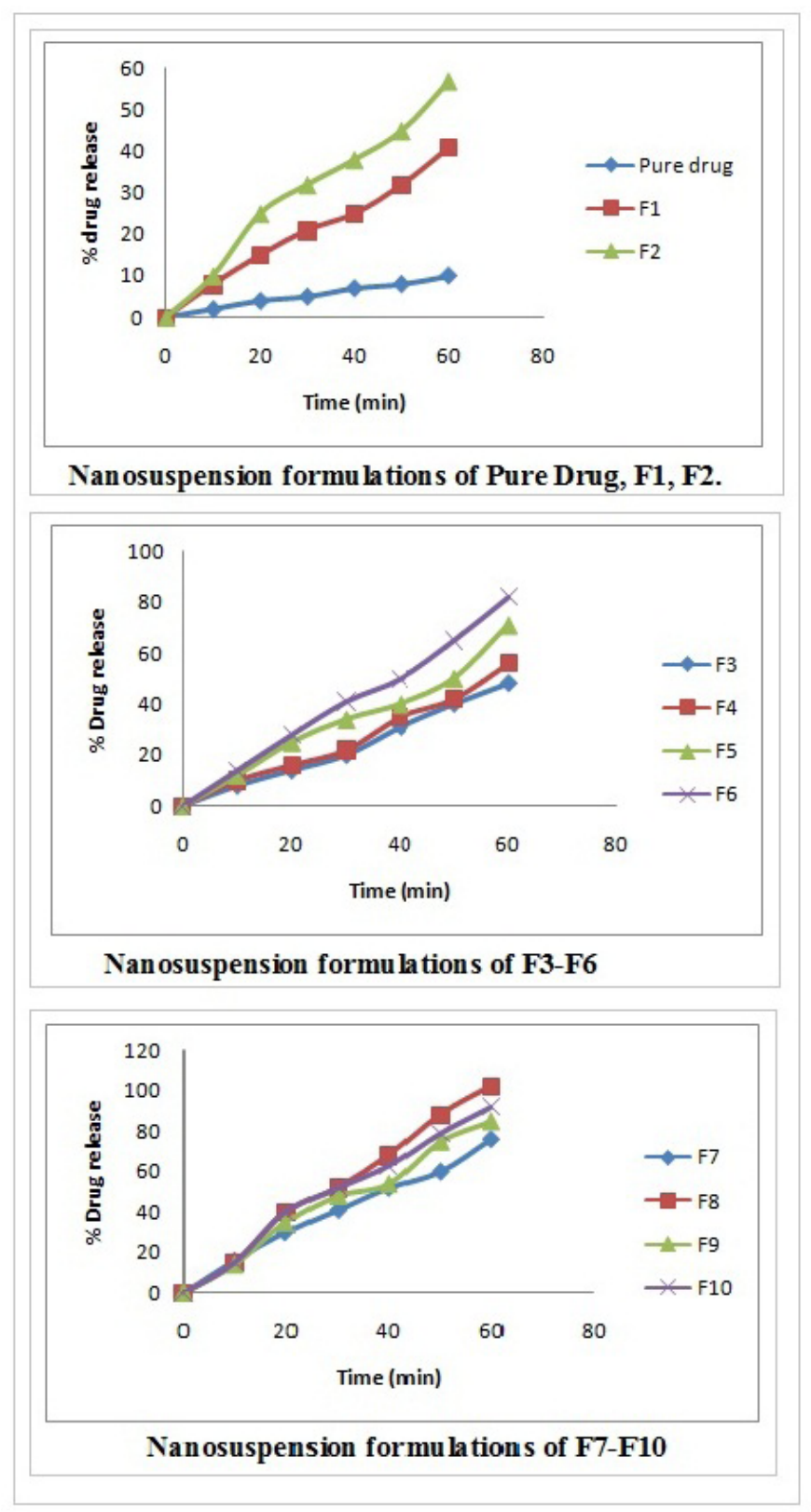

Figure 6: In-vitro dissolution Profiles of meropenem nanosuspensions and pure form of drug. 




First order plots of F1 to F4 formulations



First order plots of F5 to F8 formulations

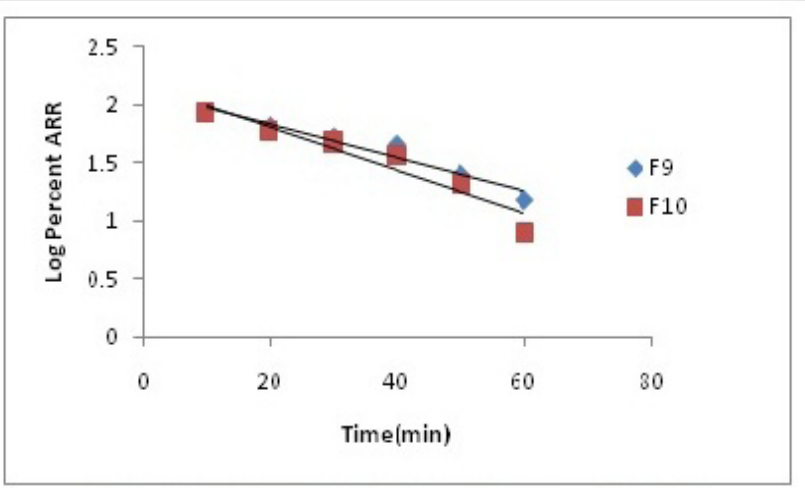

First order plots of F9 to F10 formulations



Zero order plot of F1 to F4

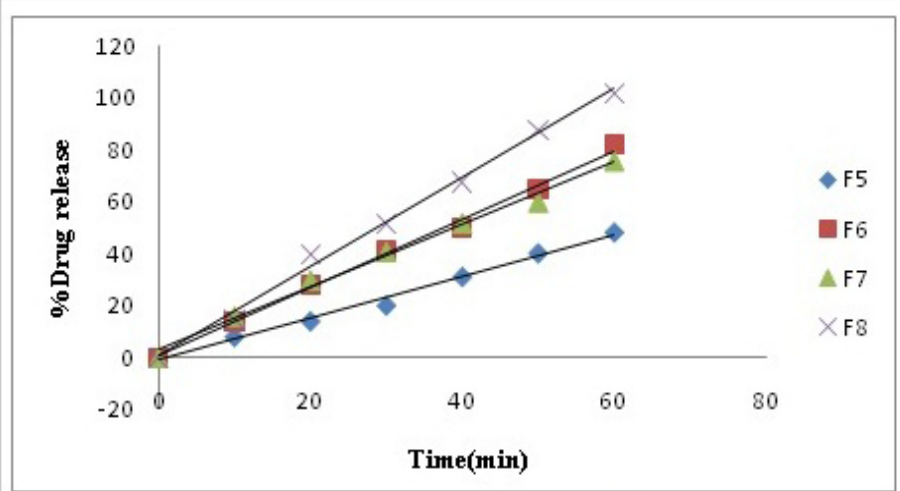

Zero order plot of $\mathbf{F 5}$ to $\mathrm{FB}$

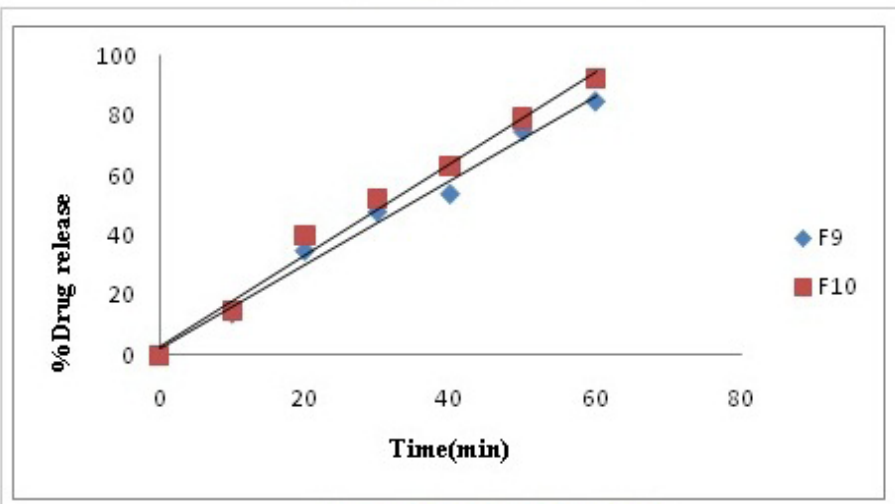

Zero order plot of F9 and F10

Figure 7: First order and Zero order kinetic plots of meropenem nanosuspensions.

are shown in Figure 7. Hence the drug release from the nanosuspensions followed first order kinetics, correlation coefficient values of Hixson Crowell model was greater than Higuchi kinetics (Table 2), indicates the drug release follows Hixson Crowell cube root kinetics. Hence change in surface area to volume with time could be the probable reasons for increased solubility and dissolution of poorly soluble meropenam on nanonization. ${ }^{20}$

\section{Stability studies}

The stability study results of nanosuspensions showed that there is no significant change with respect to the various parameters like particle size, moisture content, zeta potential, solubility and dissolution before and after storage for a period of 6 months as per ICH guidelines. Hence the nanosuspension are found to be stable at the normal room temperature. 
Table 1: Formulation of Meropenem Nanosuspensions

\begin{tabular}{ccccccccccc}
\hline Ingredients & F1 & F2 & F3 & F4 & F5 & F6 & F7 & F8 & F9 & F10 \\
\hline Meropenem (mg) & 400 & 400 & 400 & 400 & 400 & 400 & 400 & 400 & 400 & 400 \\
HPMC E-15 (mg) & 100 & 200 & 300 & 400 & 300 & 300 & 300 & 300 & 300 & 300 \\
$\quad$ SLS (mg) & 50 & 50 & 50 & 50 & 100 & 150 & 200 & 150 & 150 & 150 \\
$\begin{array}{c}\text { DCM +Methanol } \\
\quad(1: 1)(\mathrm{ml})\end{array}$ & 10 & 10 & 10 & 10 & 10 & 10 & 10 & 10 & 10 & 10 \\
$\begin{array}{c}\text { Time of sonication } \\
(\text { min) }\end{array}$ & 15 & 15 & 15 & 15 & 15 & 15 & 15 & 20 & 25 & 30 \\
\hline
\end{tabular}

Table 2: Evaluation of Meropenem Nanosuspensions

\begin{tabular}{|c|c|c|c|c|c|c|c|c|}
\hline $\begin{array}{l}\text { Formulation } \\
\text { code }\end{array}$ & $\begin{array}{c}\text { Particle } \\
\text { size }(n m) \pm S . D^{*}\end{array}$ & $\begin{array}{c}\text { Zeta } \\
\text { potential }(\mathrm{mV}) \pm S . \mathrm{D}^{*}\end{array}$ & $\begin{array}{l}\text { Solubility } \\
(\mathrm{mg} / \mathrm{ml}) \pm S \cdot D^{*}\end{array}$ & $\% \mathrm{E} . \mathrm{E} \pm \mathrm{S} . \mathrm{D}^{*}$ & $\begin{array}{l}\text { Drug content } \\
(\%) \pm S . D^{*}\end{array}$ & $\begin{array}{c}\text { Dissolution } \\
\text { efficiency at } 30 \\
\text { min } \\
(\%) \pm S . D^{*}\end{array}$ & $\begin{array}{l}\text { First order } \\
\left(r^{2} \text { values }\right)\end{array}$ & $\begin{array}{c}\text { Hixson } \\
\text { Crowell } \\
\text { ( } r^{2} \text { values) }\end{array}$ \\
\hline Pure drug & $*_{n}=3$ & $*_{n}=3$ & $8 \pm 0.43$ & $* n=3$ & $*_{n}=3$ & 32.21 & $*_{n}=3$ & $*_{n}=3$ \\
\hline $\mathrm{F} 1$ & $1498 \pm 2.1$ & $-54.2 \pm 0.02$ & $70.2 \pm 0.019$ & $52.5 \pm 0.03$ & $94.2 \pm 0.21$ & $52.1 \pm 0.03$ & 0.944 & 0.965 \\
\hline F2 & $1251 \pm 3.8$ & $-42.0 \pm 0.13$ & $67.2 \pm 0.01$ & $68.42 \pm 0.01$ & $90.24 \pm 0.06$ & $65.1 \pm 0.09$ & 0.985 & 0.896 \\
\hline F3 & $1652 \pm 3.8$ & $-28.2 \pm 1.02$ & $94.2 \pm 0.07$ & $78.2 \pm 0.41$ & $94.2 \pm 0.009$ & $74.2 \pm 0.79$ & 0.984 & 0.972 \\
\hline F4 & $501 \pm 1.4$ & $-32.0 \pm 0.01$ & $74.1 \pm 0.007$ & $73.82 \pm 0.19$ & $90.8 \pm 0.09$ & $81.2 \pm 0.18$ & 0.988 & 0.942 \\
\hline F5 & $400 \pm 1.6$ & $-31.5 \pm 0.21$ & $85.52 \pm 0.005$ & $86.82 \pm 0.23$ & $92.55 \pm 0.43$ & $75.1 \pm 0.13$ & 0.992 & 0.965 \\
\hline F6 & $102 \pm 2.9$ & $-28.2 \pm 0.05$ & $102.5 \pm 0.008$ & $80.2 \pm 1.01$ & $95.21 \pm 0.79$ & $66.5 \pm 0.01$ & 0.994 & 0.953 \\
\hline F7 & $42 \pm 2.6$ & $-42.5 \pm 0.09$ & $94.2 \pm 0.012$ & $89.2 \pm 1.05$ & $95.00 \pm 0.08$ & $56.2 \pm 0.82$ & 0.991 & 0.954 \\
\hline F8 & $2.0 \pm 3.3$ & $-28.3 \pm 0.06$ & $128.6 \pm 0.016$ & $92.6 \pm 0.02$ & $95.62 \pm 1.09$ & $92.6 \pm 0.23$ & 0.952 & 0.989 \\
\hline F9 & $20 \pm 2.8$ & $-15.2 \pm 0.79$ & $105.5 \pm 0.05$ & $88.6 \pm 0.009$ & $93.8 \pm 0.01$ & $88.2 \pm 0.41$ & 0.982 & 0.978 \\
\hline F10 & $28 \pm 1.5$ & $-10.5 \pm 0.43$ & $120.3 \pm 0.015$ & $88.2 \pm 0.51$ & $94.2 \pm 0.07$ & $86.2 \pm 0.12$ & 0.962 & 0.980 \\
\hline
\end{tabular}

\section{CONCLUSION}

Emulsification solvent evaporation method was employed in the preparation of nanosuspensions of meropenem, a poorly soluble drug. Changing the operation parameters such as sonication time and the concentration of solubilizer and stabilizer, the various nanosuspension formulations were developed to get the particle size in nano range. The optimum size range obtained with nanosuspension containing $300 \mathrm{mg}$ HPMC E 15, $150 \mathrm{mg}$ SLS for 25 minutes of sonication time. The solubility and dissolution of meropenem is significantly increased compare with the pure drug suspension. The enhanced dissolution of drug is due to decreased particle size as well as hydration of drug by hydrophilic polymer and solubilizer. In conclusion, emulsification solvent evaporation method is a simple and effective approach to produce nanosized particles of poorly water soluble drugs.

\section{ACKNOWLEDGEMENT}

Authors are thankful to the Aurobindo Pharma ltd., Hyderabad for providing the meropenem as gift sample and would like to acknowledge the management of Raghavendra Institute of Pharmaceutical Education and research for providing the facilities to execute this research work.

\section{CONFLICT OF INTEREST}

NONE.

\section{ABBREVIATION USED}

BCS: Biopharmaceutical classification System; FTIR: Fourier Transform Infrared; SEM: Scanning Electron Microscopy; DSC: Differential Scanning Calorimetry; HPMC: Hydroxy Propyl Methyl Cellulose; SLS: Sodium Lauryl Sulphate; DE: Dissolution Efficiency; AUC: Area Under the Curve; DCM: Di-Chloro methane; E.E: Entrapment efficiency; S.D: Standard Deviation. 


\section{REFERENCES}

1. Gupta H, Bhandari $D$, Sharma A. Recent trends in oral drug delivery: a review. Recent patents on drug delivery and formulation. 2009;3(2):162-73.https://doi. org/10.2174/187221109788452267.

2. Savjani KT, Gajjar AK, Savjani JK. Drug solubility: importance and enhancement techniques. ISRN Pharmaceutics. 2012.https://doi.org/10.5402/2012/195727; PMid:22830056 PMCid:PMC3399483.

3. Kumar $P$, Singh $C$. A study on solubility enhancement methods for poorly water soluble drugs. American Journal of Pharmacological Sciences. 2013;1(4):67-73. https://doi.org/10.12691/ajps-1-4-5.

4. Vuppalapati L, Cherukuri S, Neeli V, Reddy YP, Reddy KB. Application of Central Composite Design in Optimization of Valsartan Nanosuspension to Enhance its Solubility and Stability. Current Drug Delivery. 2016;13(1):143-57. https://doi.org /10.2174/1567201812666150724094358; PMid:26205900.

5. Khadka P, Ro J, Kim H, Kim I, Kim JT, Kim H, et al. Pharmaceutical particle technologies: an approach to improve drug solubility, dissolution and bioavailability. Asian Journal of Pharmaceutical Sciences. 2014;9(6):304-16. https://doi. org/10.1016/j.ajps.2014.05.005

6. Wiseman LR, Wagstaff AJ, Brogden RN, Bryson HM. Meropenem. Drugs. 1995;50(1):73-101. https://doi.org/10.2165/00003495-199550010-00007; PMid:7588092.

7. Yu LX, Amidon GL, Polli JE, Zhao H, Mehta MU, et al. Biopharmaceutics classification system: the scientific basis for biowaiver extensions. Pharmaceutical Research. 2002;19(7):921-5. https://doi.org/10.1023/A:1016473601633.

8. Sareen S, Mathew G, Joseph L. Improvement in solubility of poor water-soluble drugs by solid dispersion. International Journal of Pharmaceutical Investigation. 2012;2(1):12. https://doi.org/10.4103/2230-973X.96921; PMid:23071955 PMCid:PMC3465159

9. Nandakumar V, Geetha V, Chittaranjan S, Doble M. High glycolic poly (DL lactic co glycolic acid) nanoparticles for controlled release of meropenem. Biomedicine and Pharmacotherapy. 2013;67(5):431-6. https://doi.org/10.1016/j. biopha.2013.02.004; PMid:23583192.

10. Pinon-Segundo E, Nava-Arzaluz MG, Lechuga-Ballesteros D. Pharmaceutical polymeric nanoparticles prepared by the double emulsion- solvent evaporation technique. Recent Patents on Drug Delivery and Formulation. 2012;6(3):224-35. https://doi.org/10.2174/187221112802652606.

11. Greenhalgh DJ, Williams AC, Timmins P, York P. Solubility parameters as predictors of miscibility in solid dispersions. Journal of Pharmaceutical Sciences. 1999;88(11):1182-90. https://doi.org/10.1021/js9900856; PMid:10564068.

12. Jain S, Patel N, Lin S. Solubility and dissolution enhancement strategies: current understanding and recent trends. Drug development and industrial pharmacy. 2015;41(6):875-87. https://doi.org/10.3109/03639045.2014.971027; PMid:25342479.

13. Prasertmanakit S, Praphairaksit N, Chiangthong W, Muangsin N. Ethyl Cellulose Microcapsules for Protecting and Controlled Release of Folic Acid. AAPS Pharm Sci Tech. 2009:10(4):1104. https://doi.org/10.1208/s12249-009-9305-3: PMid:19763838 PMCid:PMC2799571.

14. Anderson NH, Bauer $\mathrm{M}$, Boussac N, Khan-Malek $\mathrm{R}$, Munden $\mathrm{P}$, et al. An evaluation of fit factors and dissolution efficiency for the comparison of in vitro dissolution profiles. Journal of Pharmaceutical and Biomedical Analysis. 1998;17(4):811-22. https://doi.org/10.1016/S0731-7085(98)00011-9.

15. Paus R, Prudic A, Ji Y. Influence of excipients on solubility and dissolution of pharmaceuticals. International Journal of Pharmaceutics. 2015;485(1):277-87. https://doi.org/10.1016/j.ijpharm.2015.03.004; PMid:25749073.

16. Rabinow BE. Nanosuspensions in drug delivery. Nature reviews. Drug discovery. 2004;3(9):785. https://doi.org/10.1038/nrd1494; PMid:15340388.

17. Yadollahi R, Vasilev K, Simovic S. Nanosuspension technologies for delivery of poorly soluble drugs. Journal of Nanomaterials. 2015;2015:1. https://doi. org/10.1155/2015/216375.

18. Colombo A, Ribotta PD, LEOn AE. Differential scanning calorimetry (DSC) studies on the thermal properties of peanut proteins. Journal of agricultural and food chemistry. 2010;58(7):4434-9. https://doi.org/10.1021/jf903426f; PMid:20222749

19. Clogston JD, Patri AK. Zeta potential measurement. Methods in Molecular Biology (Clifton, NJ). 2011;697:63-70.https://doi.org/10.1007/978-1-60327-198-1_6; PMid:21116954.

20. Siepmann J, Siepmann F. Mathematical modeling of drug dissolution. International Journal of Pharmaceutics. 2013;453(1):12-24. https://doi.org/10.1016/j. ijpharm.2013.04.044; PMid:23618956.

Article History: Submission Date : 18-03-2017; Revised Date : 16-04-2017; Acceptance Date : 28-05-2017.

Cite this article: Kumari SCH, Devi UP, Haritha A, Lava Kumar V, Sowmya C. Solubility and Dissolution Enhancement of Meropenem by Nano Suspension Approach. J Young Pharm. 2017;9(3):429-35. 